\title{
Shocks and Transitions from Career Jobs to Bridge Jobs and Retirement: A New Approach
}

\author{
John Ameriks, Joseph Briggs, Andrew Caplin, Minjoon Lee, \\ Matthew D. Shapiro, and Christopher Tonetti
}

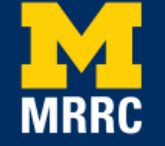

Project \#: R-UM17-04 


\title{
Shocks and Transitions from Career Jobs to Bridge Jobs and Retirement: A New Approach
}

\author{
John Ameriks \\ The Vanguard Group, Inc. \\ Joseph Briggs \\ Federal Reserve Board \\ Andrew Caplin \\ New York University and NBER \\ Minjoon Lee \\ Carleton University \\ Matthew D. Shapiro \\ University of Michigan and NBER \\ Christopher Tonetti \\ Stanford University and NBER
}

February 2018

\author{
Michigan Retirement Research Center \\ University of Michigan \\ P.O. Box 1248 \\ Ann Arbor, MI 48104 \\ www.mrrc.isr.umich.edu \\ (734) 615-0422
}

\section{Acknowledgements}

The research reported herein was performed pursuant to a grant from the U.S. Social Security Administration (SSA) funded as part of the Retirement Research Consortium through the University of Michigan Retirement Research Center Award RRC08098401-09. The opinions and conclusions expressed are solely those of the author(s) and do not represent the opinions or policy of SSA or any agency of the federal government, the Federal Reserve Board, the University of Michigan, or the Vanguard Group Inc.. Neither the United States government nor any agency thereof, nor any of their employees, makes any warranty, express or implied, or assumes any legal liability or responsibility for the accuracy, completeness, or usefulness of the contents of this report. Reference herein to any specific commercial product, process or service by trade name, trademark, manufacturer, or otherwise does not necessarily constitute or imply endorsement, recommendation or favoring by the United States government or any agency thereof.

\section{Regents of the University of Michigan}

Michael J. Behm, Grand Blanc; Mark J. Bernstein, Ann Arbor; Shauna Ryder Diggs, Grosse Pointe; Denise Ilitch, Bingham Farms; Andrea Fischer Newman, Ann Arbor; Andrew C. Richner, Grosse Pointe Park; Ron Weiser, Ann Arbor; Katherine E. White, Ann Arbor; Mark S. Schlissel, ex officio 


\title{
Shocks and Transitions from Career Jobs to Bridge Jobs and Retirement: A New Approach
}

\begin{abstract}
How much of retirement decision is driven by health? Recovering this relationship is challenging, since for each retiree one typically observes the age at which they retired given the health path they actually experienced. Because one cannot directly observe at what age they would have retired had their health been different, inferences about potential changes in the trajectory of health must necessarily be model-based. This paper provides a novel strategy for assessing the effects of changing health. Older workers participating in the Vanguard Research Initiative (VRI) report the conditional likelihood (on a 0-100 percent chance scale) that they will be working to specified horizons under alternative health scenarios. They also report their unconditional likelihoods of working to those horizons and of experiencing those health states. Using these data this paper delivers novel, individual and aggregate level, estimates of the subjective ex ante treatment effects (SATE) of health on retirement age, given by the difference between respondents' likelihoods of working in low versus high health. The SATEs of health on labor supply at 2 and 4 years horizons equal 0 for almost 30\% of the respondents. The remaining $70 \%$ reports subjective expectations which imply a strictly negative SATE (median $=40$ percent and std. dev. $=24$ percent for the 2 year horizon). A rich set of covariates and the unconditional expectations measures shed light on dimensions of heterogeneity in SATEs.
\end{abstract}

\section{Citation}

Ameriks, John, Joseph Briggs, Andrew Caplin, Minjoon Lee, Matthew D. Shapiro, and Matthew D. Shapiro. 2018. "Shocks and Transitions from Career Jobs to Bridge Jobs and Retirement: A New Approach.” Ann Arbor MI: University of Michigan Retirement Research Center (MRRC) Working Paper, WP 2018-380. http://mrrc.isr.umich.edu/wp380/

\section{Authors' acknowledgements}

The findings and conclusions expressed are solely those of the author(s) and do not represent the views of SSA, any agency of the federal government, Bocconi University, the University of Michigan, the Michigan Retirement Research Center at the University of Michigan, or the Vanguard Group Inc. We thank Feiya Shao and Ann Rodgers for excellent research assistantship. The research uses data from the Vanguard Research Initiative (VRI) what was developed by a research team under a program project grant from the National Institute on Aging P01-AG026571. The Vanguard Group Inc. supported the data collection of the VRI. Vanguard's Client Insight Group and IPSOS SA were responsible for implementing the VRI survey and provided substantial input into its design. John Ameriks, Andrew Caplin, and Matthew D. Shapiro are co-principal investigator of the VRI. The design of the VRI benefited from the collaboration and assistance of Joseph Briggs, Wandi Bruine de Bruin, Alycia Chin, Mi Luo, Minjoon Lee, Brooke Helppie McFall, Ann Rodgers, and Christopher Tonetti as part of the program project, from Annette Bonner (Vanguard), and Wendy O’Connell (IPSOS SA). This project uses Survey 4 of the VRI that was designed by Ameriks, Briggs, Caplin, Lee, Shapiro, and Tonetti. For documentation of the VRI, including a dynamic link to the survey instrument, see http://ebp-projects.isr.umich.edu/VRI/. 


\title{
New Evidence on Transitions to Post-Career Employment
}

\author{
John Ameriks, ${ }^{1}$ Joseph Briggs, ${ }^{2}$ Andrew Caplin, ${ }^{3}$ \\ Minjoon Lee, ${ }^{4}$ Matthew D. Shapiro, ${ }^{5}$ and Christopher Tonetti ${ }^{6}$ \\ ${ }^{1}$ The Vanguard Group, Inc. \\ ${ }^{2}$ Federal Reserve Board \\ ${ }^{3}$ New York University and NBER \\ ${ }^{4}$ Carleton University \\ ${ }^{5}$ University of Michigan and NBER \\ ${ }^{6}$ Stanford GSB and NBER
}

\section{Introduction}

Extending the length of working $l$ ife can be much nore effective in securing financial well-being in retirement than i ncreasing saving rate while working (Bronshtein, Scott, Shoven and Slavov, 2018). An improved understanding of transition patterns i nto post-carer employment is i mportant. When and why do Americans l eave their career j ob, defined as the nost i mportant j ob they had in their working career? What j ob characteristics encourage them to stay l onger in the career job? After l eaving the career j ob, how many of them directly transition i nto r etirement and how nany have a post-career bridge job? What job characteristics do they look for when they search for a post-career employment opportunity? 
This paper provides a rich set of empirical evidence on these questions that comes from a new survey implemented under the Vanguard Research Initiative. The survey focuses on measuring late-life labor market activities of American households. The questionnaire features following innovations:

- It measures detailed job characteristics not only of a career job but also of post-career bridge jobs.

- It examines reasons of leaving a career job and whether households would have changed their decisions under counterfactual situations.

- It examines post-career job search behavior of households.

The paper finds that, even though a direct transition from a career job to full retirement is still the most common pattern, a significant fraction of older Americans reveal interest for working beyond the career job. $38 \%$ of the sample had a post-career bridge job and another $7 \%$ of them looked for a post-career employment opportunity. Bad health or bad business conditions were the main reason for leaving the career job for a minority of those who left career jobs. But for this minority, had they counterfactually had better health or economic conditions, they likely would have decided to continue working. We also find that those who work longer on their career job or have a post-career bridge job tend to work fewer hours, have a flexible schedule, and receive lower hourly wages. This suggests that older Americans value having less work burden and more flexibility in their work, which is also supported by post-career job search behavior. By investigating the wage gap between career and bridge jobs, we find that fewer working hours, the length of gap between the two jobs, and changing occupation or industry in this transition all contribute to lower hourly wage on bridge jobs.

This paper contributes to growing empirical literature that examines late-in-life labor market activities. Ruhm (1990), Maestas (2010), and Rupert and Zanella (2015) document that having a post-career bridge job is becoming more common. Many of these jobs are part time or lower paid (Cassanova, 2013), even when these are self-employment (Ramnath, Shoven, and Slavov, 2017), suggesting that a post-career bridge job is used as a transition path to full retirement. We contribute to this literature by documenting characteristics of post-career bridge jobs, transitions from career to bridge jobs, and search behavior for post-career job opportunities in detail.

This paper also relates to the literature that uses survey questions to examine factors that affect late-in-life labor supply decisions. Factors studied in this literature include shares of older workers 
(Blau and Shvydko, 2011), career attachment and job satisfaction (Gobeski and Beehr, 2009), pension and hours arrangements (van Soest, Kapteyn and Zissimopoulos, 2007, van Soest and Vonkova, 2014, and Kantarci and van Soest, 2015), and disability (Kapteyne, Smith and van Soest, 2007). The survey used in our study not only directly asks for reasons of leaving jobs but also what workers would have done under counterfactual situations including health changes, business conditions and part-time options to understand importance of these factors in retirement decisions.

\section{Sample and Survey}

This paper uses the Vanguard Research Initiative (VRI), a linked survey-administrative data from a large sample of older account holders at a mutual fund company, the Vanguard Inc. Among the five internet surveys that have been implemented so far, the fourth survey (Survey 4) focuses on the late-in-life labor supply. Survey 4 asks detailed questions regarding job history, for both career and bridge jobs, reasons of quitting the jobs, as well as search behaviors on and after a career job. In this section we first describe the sample and then the survey we use in this paper.

\subsection{Sample}

The VRI is composed of a sample of account holders at Vanguard who are at least 55 years old. To be in the sample, we require that they have at least $\$ 10,000$ at their Vanguard accounts to ensure their non-trivial engagement with Vanguard and they have an access to internet since the surveys are implemented online. The entire sample size of the VRI is about 9,000, comparable to the size of each cross-section of the Health and Retirement Studies (HRS).

We use 2,772 respondents who completed Survey 4 that is the main source of data for this paper. ${ }^{1}$ Table 1 shows the sample characteristics including age, marital status, and education level. The sample is roughly equally representing each 5-year age bin above age 55 up to 75 and then those who are older than 75. One third of them are female. Two thirds of them live with a spouse or a partner. More than 70 percent have a college degree and more than 40 percent had post-college education. On the 5-point scale \{excellent, very good, good, fair, poor\}, the vast majority report that their health is very good or better, while only a tiny fraction of respondents report that it is fair or worse. We refer to Ameriks,

\footnotetext{
${ }^{1}$ There are five internet surveys implemented so far. Each survey focused on different subject matters, including sample's financial situation, preferences about long-term care and bequest, intergenerational relationships, etc. Survey 4 focuses on labor history and preferences about labor supply in late life.
} 
Caplin, Lee, Shapiro and Tonetti (2014) for more detailed descriptions of the sample including their financial wealth.

Table 1: VRI sample characteristics

\begin{tabular}{|c|c|c|c|c|c|c|}
\hline \multirow{10}{*}{$\begin{array}{l}\text { Age: } \\
\text { Financial wealth: }\end{array}$} & \multicolumn{6}{|c|}{ Age and Wealth } \\
\hline & $10 p$ & $25 p$ & $50 p$ & $75 p$ & $90 p$ & Mean \\
\hline & $\overline{60}$ & $\overline{64}$ & $\overline{69}$ & $\frac{1}{75}$ & $\overline{79}$ & $\overline{70}$ \\
\hline & 172,665 & 394,041 & 821,252 & $1,495,714$ & $2,621,855$ & $1,248,491$ \\
\hline & \multicolumn{2}{|c|}{ Married } & & \multicolumn{3}{|c|}{ Education } \\
\hline & Yes & No & & $<$ College & College & $>$ College \\
\hline & $67 \%$ & $33 \%$ & & $24 \%$ & $32 \%$ & $44 \%$ \\
\hline & \multicolumn{2}{|c|}{ Sex } & & \multicolumn{3}{|c|}{ Health } \\
\hline & Female & Male & & $\begin{array}{l}\text { Excellent/ } \\
\text { Very Good }\end{array}$ & Good & $\begin{array}{l}\text { Fair/ } \\
\text { Poor }\end{array}$ \\
\hline & $34 \%$ & $66 \%$ & & $73 \%$ & $22 \%$ & $5 \%$ \\
\hline
\end{tabular}

Notes: Survey 4 respondents. N=2,772. Financial wealth is from survey 1 and adjusted to $2015 \$$.

By construction, the VRI is not a representative sample of older Americans. Compared to the HRS sample, the VRI sample is wealthier, healthier, and more educated. Ameriks, Caplin, Lee, Shapiro and Tonetti (2014), however, shows that a subset of the HRS sample that satisfy a similar set of sampling criteria (i.e., having at least $\$ 10,000$ in their non-transactional accounts and an internet access) have similar characteristics as the VRI sample. Table A1 in Appendix A indeed shows that the VRI-eligible HRS sample has similar demographics as the VRI sample, though the latter is still slightly more educated and healthier. In Section 3, we will also show that the job history of that subset of the HRS sample is similar to that from the VRI sample. So the VRI is essentially zooming into a subset of older American population who are wealthier, healthier, and more educated. This is a group of people whose job-related human capital may not depreciate quickly (because of them being relatively healthier in late life and types of jobs they typically have not being physically demanding as we show in the next section), so it is important to ask what is behind sudden withdrawals from labor force among this group. 


\subsection{Survey}

Survey 4 is composed of two parts. In the first part, it asks detailed questions about job history and search behavior. In the second part, it asks hypothetical survey questions (SSQs) that are designed to measure preferences regarding labor supply late in life that are not fully reflected in the behavioral data. This paper focuses on the former. For the findings from the latter, see Ameriks, Briggs, Caplin, Lee, Shapiro and Tonetti (2017).

The aim of the behavioral part of the survey is to establish the common retirement patterns in the sample and to understand what job characteristics encourage Americans to stay longer in the labor force. To serve this purpose it collects a detailed set of data not only on the characteristics of the jobs but also on the transitions between the jobs and also between working-phase and retirement. It first records detailed job characteristics including hourly wage, number of working hours, types of industry and occupation, the length of tenure, and whether the work schedule was flexible. It first asks about these characteristics of the career job, that is defined as the most important or the longest job respondents had since age 40. It then asks about characteristics of a post-career job, which is labeled as a bridge job in the survey. In case respondents had multiple bridge jobs, it asks about the most recent one. The survey then asks why they quit the jobs. It further asks about their search behavior on and after the career job. By examining how long they worked on the career job, whether they had a bridge job after the career job, and whether they searched for a job opportunity after the career job, we can better understand how willing to work Americans are in late life. Also, by examining under which working environment workers stay longer at the career job, how bridge jobs are different than the career job, and what they looked for when they searched for a post-career job opportunity, we can shed light on to what job characteristics Americans are attracted to in late life.

Depending on whether respondents are currently working or not, and also on whether they had a bridge job after their career job, respondents take different paths in this part of the survey. Figure 1 overviews the flow of the survey in each case as well as the main questions asked in each module of this survey.

\section{Labor Market Activity Late-in-Life: Career Jobs}

In this section we document a detailed work history of the sample. The main motivation of this section is twofold. First, we want to understand what are the common patterns of retirement among 
Figure 1: Flow of the work history part of Survey 4

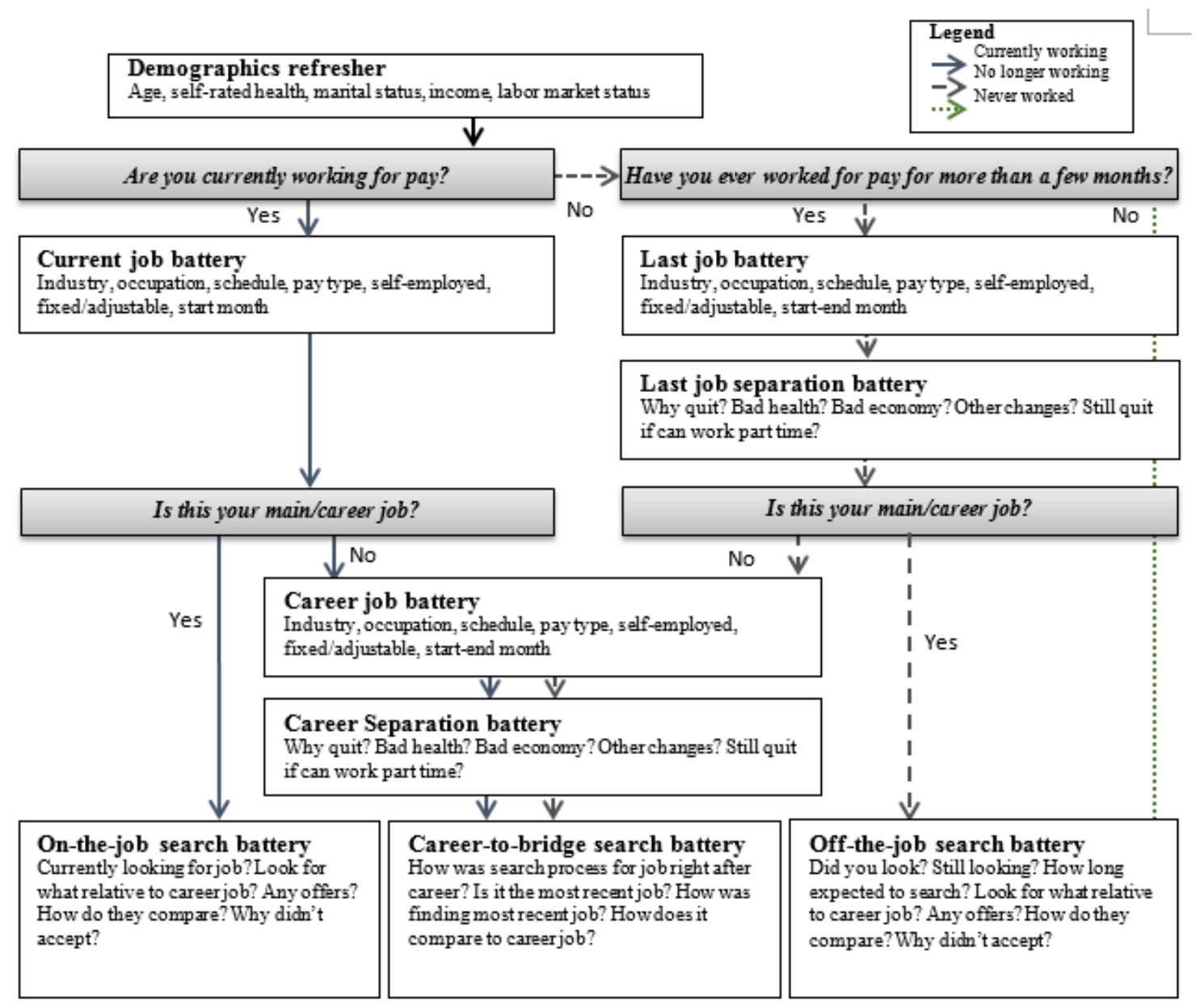

older Americans. Second, analyses on behavioral data also hint on what job characteristics encourage workers to stay in the labor force longer. We first start with descriptions of the current labor force participation. Then we examine common characteristics of career jobs and the exit patterns from those jobs. Lastly we examine labor market activity after the separation from career jobs, including having a bridge job and searching for such an opportunity. ${ }^{2}$

\subsection{Current Labor Force Participation}

Table 2 shows the distribution of self-reported labor force participation status. Before age 60 the vast majority of the sample are working while many retire between age 60 and 65 . Only about a quarter in the age range between 65 and 69 are working. The share of working respondents becomes very small

\footnotetext{
${ }^{2}$ Whenever corresponding variables are available in the HRS, we will present tabulations on the HRS sample (both entire and the VRI-eligible) in Appendix A. Many results in this Section, however, are based on survey questions that are first implemented in the VRI.
} 
after age 70. Another important pattern to notice is that, once they retire, a vast majority consider themselves being completely retired. We find a similar pattern in the HRS (Table A2 in Appendix A), though a fraction of partial retirement is slightly higher in the HRS.

Table 2: Labor force participation status

\begin{tabular}{lccccccc}
\hline \hline & \multicolumn{9}{c}{ By Age } & & Total \\
\cline { 2 - 7 } \cline { 4 - 6 } & $\frac{\mathbf{5 5 - 5 9}}{11.0}$ & $\underline{\mathbf{6 0 - 6 4}}$ & $\underline{\mathbf{6 5 - 6 9}}$ & $\underline{\mathbf{7 0 - 7 4}}$ & $\underline{\mathbf{7 5 -}}$ & \\
Retired, completely (\%) & 11.8 & 68.1 & 82.6 & 90.3 & 64.7 \\
Retired, not completely (\%) & 2.9 & 5.4 & 4.8 & 5.1 & 3.6 & 4.5 \\
Not retired (\%) & 86.1 & 61.9 & 27.1 & 12.3 & 6.2 & 30.8 \\
$N$ & 273 & 522 & 646 & 632 & 699 & 2,772 \\
\hline \hline
\end{tabular}

A sudden dropout from the labor force between age 60 and 65 is a well established pattern in the literature. Incentives created by Social Security and Medicare rules might explain a significant part of this transition (French, 2005, French and Jones, 2011). It could also be driven by changes in households' preference about labor supply over age; by preference from firms' side, if the productivity of workers suddenly decreases (or is perceived to decrease) in that age range; or by mismatches between what job characteristics older Americans want and what firms want to offer to them. Examination on the job characteristics that become more common among older Americans and their job search behaviors on or after the career job shed more light on the factors behind these transitions as we show below.

\subsection{Career Job Characteristics}

Before we start analyzing transitions to retirement, we first examine what the sample was (is) doing in their career jobs. Table 3 presents key characteristics of career jobs of the sample, separately for those who retired from their career jobs and those who are still working on their career jobs. Most of the career jobs are full time jobs. The most common number of working hours is 2,080 per year, which is 40 hours per week for 52 weeks. They typically worked for fairly long in their career jobs. More than half of the sample worked for more than 20 years. The most common industry is professional, scientific, and technical services while the most common occupation is management. Self-employment is rare and also most of them did not have a flexible schedule. In short, we are examining labor market transitions of those who were mainly employed on a long, full time career job, that are typically more 
professional and less physically demanding, and typically had no flexibility in schedule. For the set of characteristics that are also measured in the HRS including the length of tenure, industries and occupations, the number of work hours and salary, we find them to be similar between the VRI sample and the VRI-eligible HRS sample (see Appendix Table A4). ${ }^{3}$

\footnotetext{
${ }^{3}$ The VRI sample tends to have a higher salary and is more likely to have an occupation in management compared to the entire HRS sample (see Appendix Table A3).
} 
Table 3: Career Job Characteristics

\begin{tabular}{|c|c|c|c|c|c|c|}
\hline \multirow[t]{2}{*}{ A. Retired from career job } & \multicolumn{6}{|c|}{ Years worked, salary, hours worked } \\
\hline & $\underline{10 p}$ & 25p & $\underline{50 p}$ & $\underline{75 p}$ & 90p & $\underline{\text { Mean }}$ \\
\hline Years worked: & 8 & 14 & 22 & 31 & 37 & 22 \\
\hline Salary (in 2015\$): & 30,866 & 58,253 & 91,467 & 133,398 & 196,379 & 111,698 \\
\hline Hours worked (per year): & 1,260 & 1,924 & 2,080 & 2,184 & 2,600 & 2,027 \\
\hline \multirow[t]{2}{*}{ Self-employed: } & \multicolumn{5}{|l|}{ Yes } & $6.9 \%$ \\
\hline & \multicolumn{5}{|l|}{ No } & $93.1 \%$ \\
\hline \multirow{2}{*}{ Had a flexible schedule: } & \multicolumn{5}{|l|}{ Yes } & $27.6 \%$ \\
\hline & \multicolumn{5}{|l|}{ No } & $72.4 \%$ \\
\hline \multirow[t]{2}{*}{ Health insurance provision: } & \multicolumn{5}{|l|}{ Yes } & $86.2 \%$ \\
\hline & \multicolumn{5}{|l|}{ No } & $13.8 \%$ \\
\hline \multirow[t]{3}{*}{ Most common industries: } & \multirow{2}{*}{\multicolumn{5}{|c|}{$\begin{array}{l}\text { Professional, scientific, and technical services } \\
\text { Manufacturing }\end{array}$}} & $17.8 \%$ \\
\hline & & & & & & $14.5 \%$ \\
\hline & \multicolumn{5}{|c|}{ Educational services } & $12.7 \%$ \\
\hline \multirow[t]{3}{*}{ Most common occupations: } & \multicolumn{5}{|c|}{ Management } & $25.6 \%$ \\
\hline & \multicolumn{5}{|c|}{ Education, training, library } & $10.6 \%$ \\
\hline & \multicolumn{5}{|c|}{ Business and financial operations } & $9.8 \%$ \\
\hline \multirow[t]{2}{*}{ B. Working on career job } & \multicolumn{6}{|c|}{ Years worked, salary, hours worked } \\
\hline & $\underline{10 p}$ & $25 p$ & $\underline{50 p}$ & $75 \mathrm{p}$ & 90p & Mean \\
\hline Years worked: & 8 & 14 & 21 & 30 & 38 & 22 \\
\hline Salary (in 2015\$): & 14,089 & 44,000 & 78,000 & 117,000 & 165,000 & 92,428 \\
\hline Hours worked (per year): & 480 & 1,664 & 2,080 & 2,080 & 2,600 & 1,842 \\
\hline \multirow[t]{2}{*}{ Self-employed: } & \multicolumn{5}{|l|}{ Yes } & $15.9 \%$ \\
\hline & \multicolumn{5}{|l|}{ No } & $84.1 \%$ \\
\hline \multirow[t]{2}{*}{ Had a flexible schedule: } & \multicolumn{5}{|l|}{ Yes } & $47.7 \%$ \\
\hline & \multicolumn{5}{|l|}{ No } & $52.3 \%$ \\
\hline \multirow[t]{2}{*}{ Health insurance provision: } & \multicolumn{5}{|l|}{ Yes } & $72.0 \%$ \\
\hline & \multicolumn{5}{|l|}{ No } & $28.0 \%$ \\
\hline Most common industries: & Profes & sional, s & cientifi & and tec & cal services & $18.6 \%$ \\
\hline & Manu & acturin & & & & $10.7 \%$ \\
\hline & Educa & ional se & rvices & & & $10.5 \%$ \\
\hline Most common occupations: & Mana & ement & & & & $19.1 \%$ \\
\hline & Busin & ss and & inancia & operati & & $11.3 \%$ \\
\hline & Comp & iter anc & mathe & natical & & $9.0 \%$ \\
\hline
\end{tabular}

Notes: $\mathrm{N}=2,149$ for Panel A and $\mathrm{N}=601$ for Panel B. 
The career job characteristics are overall similar between those who have already quit it and those who are still working on it, though the latter group is more likely to be self-employed and more likely to have a flexible schedule. This may be mixing two effects. On the one hand, it is due to the selection, that these are characteristics that encourage to work longer, so those who had such job characteristics are more likely to stay in their career jobs. On the other hand, those who are still working are more likely to be in younger cohorts and those characteristics might be more common to them. As a first step to disentangle these two, we turn to examine the career job characteristics for those who are still working on their career jobs over different age groups.

\subsubsection{Career Job Characteristics over Age Groups}

Table 4 tabulates career job characteristics, among those who are still working on their career jobs, for three different age groups: not older than 62, between 63 and 65, and older than 65 . The share of workers who are self-employed or have a flexible schedule increases with age, in particular after 65 . Only 9 percent of workers were self-employed before age 63 . It goes up to 34 after age 65 . The share of having a flexible schedule changes from 36 percent to 71 percent between these two age groups. This finding suggests that having more control over own work schedule either through self-employment or obtaining flexibility in schedule is attractive for older workers, so either workers with those job characteristics tend to stay longer or employers start to offer those characteristics at older ages. Older workers' preferences for these characteristics is also consistent with the findings by Ramnath, Shoven, and Slavov (2017).

There are other patterns that are worthwhile to note. The number of hours worked decreases significantly, in particular on the left tail, after age 65. This explains why flexibility in work schedule is more valued in late life. Being able to reduce the work burden at the beginning of the pathway to retirement seems to be appreciated by older workers. There is no noticeable change in hourly wage. This might be a result of declining productivity over age and workers with higher wage selecting into working longer canceling out each other. The share of jobs with health insurance provision drops significantly at age 65 . This may reflect that older workers become eligible for Medicare at this age.

There are also changes in the distribution of industries and occupations across age groups. Those who work in manufacturing or transportation and warehousing industries are less likely to stay longer while those work in professional, scientific, and technical services or educational services are more 
Table 4: Career Job Characteristics: Workers, by Age Group

\begin{tabular}{|c|c|c|c|c|c|c|}
\hline \multirow[t]{2}{*}{ A. Age $\leq 62$} & \multicolumn{6}{|c|}{ Salary, hours worked, hourly wage } \\
\hline & $10 p$ & $25 p$ & $50 p$ & $75 \mathrm{p}$ & $90 p$ & Mean \\
\hline Salary (in $2015 \$$ ): & $3 \overline{30,000}$ & $5 \overline{7,000}$ & $8 \overline{5,000}$ & $1 \overline{23,782}$ & $1 \overline{77,964}$ & $\overline{101,169}$ \\
\hline Hours worked (per year): & 1,440 & 2,080 & 2,080 & 2,340 & 2,600 & 2,062 \\
\hline Hourly wage (in $2015 \$$ ): & 19 & 28 & 40 & 58 & 85 & 51 \\
\hline \multirow[t]{2}{*}{ Self-employed: } & Yes & & & & & $8.8 \%$ \\
\hline & No & & & & & $91.2 \%$ \\
\hline \multirow[t]{2}{*}{ Had a flexible schedule: } & Yes & & & & & $36.3 \%$ \\
\hline & No & & & & & $63.7 \%$ \\
\hline \multirow[t]{2}{*}{ Health insurance provision: } & Yes & & & & & $83.0 \%$ \\
\hline & No & & & & & $17.0 \%$ \\
\hline \multirow[t]{2}{*}{ B. Age 63-65 } & \multicolumn{6}{|c|}{ Salary, hours worked, hourly wage } \\
\hline & $10 p$ & $25 p$ & $50 p$ & $75 \mathrm{p}$ & $90 p$ & Mean \\
\hline Salary (in 2015\$): & $3 \overline{2,000}$ & $5 \overline{2,000}$ & $8 \overline{5,000}$ & $1 \overline{20,917}$ & $2 \overline{200,000}$ & $\overline{107,770}$ \\
\hline Hours worked (per year): & 884 & 1820 & 2,080 & 2,250 & 2,600 & 1,944 \\
\hline Hourly wage (in $2015 \$$ ): & 19 & 28 & 42 & 58 & 120 & 62 \\
\hline \multirow[t]{2}{*}{ Self-employed: } & Yes & & & & & $11.0 \%$ \\
\hline & No & & & & & $89.0 \%$ \\
\hline \multirow[t]{2}{*}{ Had a flexible schedule: } & Yes & & & & & $50.9 \%$ \\
\hline & No & & & & & $49.1 \%$ \\
\hline \multirow[t]{2}{*}{ Health insurance provision: } & Yes & & & & & $85.4 \%$ \\
\hline & No & & & & & $14.6 \%$ \\
\hline \multirow[t]{2}{*}{ C. Age $\geq 66$} & \multicolumn{6}{|c|}{ Salary, hours worked, hourly wage } \\
\hline & $10 p$ & $25 p$ & $50 p$ & $75 \mathrm{p}$ & $90 p$ & Mean \\
\hline Salary (in $2015 \$$ ): & $\overline{3,500}$ & $1 \overline{5,500}$ & $\overline{50,000}$ & $9 \overline{4,000}$ & $1 \overline{55,000}$ & 64,202 \\
\hline Hours worked (per year): & 156 & 480 & 1,540 & 2,080 & 2,160 & 1,337 \\
\hline Hourly wage (in $2015 \$$ ): & 14 & 23 & 44 & 64 & 99 & 61 \\
\hline \multirow[t]{2}{*}{ Self-employed: } & Yes & & & & & $33.7 \%$ \\
\hline & No & & & & & $66.3 \%$ \\
\hline \multirow[t]{2}{*}{ Had a flexible schedule: } & Yes & & & & & $71.2 \%$ \\
\hline & No & & & & & $28.8 \%$ \\
\hline \multirow[t]{2}{*}{ Health insurance provision: } & Yes & & & & & $39.2 \%$ \\
\hline & No & & & & & $60.8 \%$ \\
\hline
\end{tabular}

Notes: $\mathrm{N}=321$ for group $\mathrm{A}, \mathrm{N}=117$ for group $\mathrm{B}$, and $\mathrm{N}=163$ for group $\mathrm{C}$. 
Table 4: Career Job Characteristics: Workers, by Age Group (Continued)

\begin{tabular}{|c|c|c|c|}
\hline \multirow[t]{2}{*}{ D. Share of selected industries } & \multicolumn{3}{|c|}{ Age group } \\
\hline & $\leq 62$ & $\underline{63-65}$ & $\geq 66$ \\
\hline Professional, scientific, and technical services & $1 \overline{7.7 \%}$ & $17.1 \%$ & $21.5 \%$ \\
\hline Manufacturing & $12.8 \%$ & $12.0 \%$ & $5.5 \%$ \\
\hline Transportation and Warehousing & $11.8 \%$ & $8.6 \%$ & $3.1 \%$ \\
\hline Health Care and Social Assistance & $6.2 \%$ & $12.8 \%$ & $8.6 \%$ \\
\hline Educational Services & $7.5 \%$ & $6.8 \%$ & $12.9 \%$ \\
\hline \multirow[t]{2}{*}{ E. Share of selected occupations } & \multicolumn{3}{|c|}{ Age group } \\
\hline & $\leq 62$ & $\underline{63-65}$ & $\geq 66$ \\
\hline Management & $2 \overline{1.5 \%}$ & $22.2 \%$ & $12.3 \%$ \\
\hline Business and financial operations & $9.4 \%$ & $12.8 \%$ & $14.1 \%$ \\
\hline Computer and mathematical & $9.0 \%$ & $6.8 \%$ & $10.4 \%$ \\
\hline Office and administrative support & $8.7 \%$ & $10.3 \%$ & $8.6 \%$ \\
\hline Education, training, library & $4.4 \%$ & $3.4 \%$ & $11.0 \%$ \\
\hline
\end{tabular}

Notes: $\mathrm{N}=321$ for group $\mathrm{A}, \mathrm{N}=117$ for group $\mathrm{B}$, and $\mathrm{N}=163$ for group $\mathrm{C}$.

likely to stay longer. Those who have management positions tend to stay shorter while those who have education-related occupations tend to stay longer.

These findings hint what job characteristics encourage workers to stay in their career jobs, in particular after the normal retirement ages. Having control over own work schedule (either through self-employment or by having a flexible schedule) seems to be an important factor, and being able to reduce work burden at the beginning of the pathway to retirement turns out to be a key reason why they want to have it.

\subsubsection{Career Job Exits}

We now turn to the reasons why respondents left their career job. For those who already quit the career job, the survey asks the reasons (and also about the main reason in case respondents give multiple reasons) for the separation. All the listed reasons as well as the share of respondents who selected each are in Table 5. Since the reason of the separation can be very different between the group who directly transitioned into retirement after quitting the career job and those who had a bridge job after the separation, we analyze these two groups separately.

For those who did not have a post-career bridge job, the vast majority (81\%) reported retirement to be the main reason of quitting the career job. None of the other reasons is chosen to be the main reason of the separation for more than $5 \%$ of the sample. 
Table 5: Reason for Leaving (R)/Main Reason for Leaving (MR)

\section{A. Sample who had no bridge job}

$\begin{array}{lcclcc}\text { Reason } & \underline{\mathbf{R}} & \underline{\mathbf{M R}} & \underline{\text { Reason }} & \underline{\mathbf{R}} & \underline{\mathbf{M R}} \\ \text { Laid off } & 5.3 & 4.5 & \text { Retirement } & 81.8 & 81.0 \\ \text { Childcare } & 1.3 & 0.8 & \text { Famly-care/Personal obligation } & 2.5 & 1.7 \\ \text { Own Illness } & 2.0 & 1.5 & \text { Own Injury } & 0.1 & 0.1 \\ \text { School/training } & 0.0 & 0.0 & \text { Discharged/Fired } & 0.5 & 0.5 \\ \text { Closed business or bankrupt } & 1.4 & 1.4 & \text { Sold Business } & 2.2 & 1.7 \\ \text { Temporary job } & 0.6 & 0.5 & \text { Quit to other job } & 0.2 & 0.2 \\ \text { Business Conditions } & 1.2 & 0.8 & \text { Unsatisfactory arrangements (hours/pay) } & 1.5 & 1.0 \\ \text { Other } & 6.1 & 4.5 & & \end{array}$

\section{B. Sample who had a bridge job}

$\begin{array}{lcclcc}\text { Reason } & \underline{\mathbf{R}} & \underline{\mathbf{M R}} & \underline{\mathbf{R e a s o n}} & \underline{\mathbf{R}} & \underline{\mathbf{M R}} \\ \text { Laid off } & 16.4 & 14.3 & \text { Retirement } & 41.1 & 36.3 \\ \text { Childcare } & 0.3 & 0.1 & \text { Famly-care/Personal obligation } & 2.1 & 1.7 \\ \text { Own Illness } & 0.5 & 0.4 & \text { Own Injury } & 0.5 & 0.3 \\ \text { School/training } & 0.6 & 0.5 & \text { Discharged/Fired } & 3.1 & 2.9 \\ \text { Closed business or bankrupt } & 6.3 & 5.3 & \text { Sold Business } & 5.9 & 5.0 \\ \text { Temporary job } & 0.6 & 0.4 & \text { Quit to other job } & 15.2 & 13.5 \\ \text { Business Conditions } & 3.5 & 2.1 & \text { Unsatisfactory arrangements (hours/pay) } & 4.6 & 3.2 \\ \text { Other } & 16.4 & 14.0 & & & \end{array}$

Notes: $\mathrm{N}=1,337$ for group $\mathrm{A}$ and $\mathrm{N}=805$ for group $\mathrm{B}$.

For those who had a post-career bridge job, the share of those who left the career job for retirement is much lower $(36 \%)$ but still fairly high. This suggests that a significant fraction of those who end up having a post-career bridge job initially decide to retire and then change their mind to come back to the labor market. Another significant fraction of this group report that they lost their career job involuntarily. $22 \%$ of this sample had to leave the career job either because of being laid off, being discharged, or because the business was closed or went bankrupt.

To obtain a more complete picture of situation facing those who leave the career job, the survey also asks what were happening at the moment of the separation from the career job (regardless of whether they consider them to be reasons of their retirement or not). Table 6 reports the options provided and result, again separately for those who transitioned into retirement and those who had a post-career bridge job. 
Table 6: What happened at retirement

\section{A. Sample who had no bridge job}

\begin{tabular}{lcllc} 
What happened & Yes & & What happened & Yes \\
\cline { 2 - 4 } Supervisor encouraged departure & 5.1 & & Coworker encouraged departure & 1.1 \\
Wages reduced & 1.9 & Hours reduced & 1.5 \\
Would have been laid off & 4.1 & New job duties & 6.1 \\
New job location & 2.9 & Pension eligible & 22.0 \\
Employer changed health insurance & 1.2 & Early retirement incentive & 18.7 \\
Other & 11.7 & &
\end{tabular}

\section{B. Sample who had a bridge job}

\begin{tabular}{lcllc} 
What happened & Yes & & What happened & Yes \\
${$\cline { 2 - 4 }$} }$ & 9.6 & & Coworker encouraged departure & 1.2 \\
Wages reduced & 3.1 & Hours reduced & 1.5 \\
Would have been laid off & 12.1 & New job duties & 6.4 \\
New job location & 6.2 & Pension eligible & 15.2 \\
Employer changed health insurance & 0.8 & Early retirement incentive & 15.0 \\
Other & 16.3 & &
\end{tabular}

Notes: $\mathrm{N}=1,337$ for group $\mathrm{A}$ and $\mathrm{N}=805$ for group $\mathrm{B}$.

For those who did not have a post-career bridge job, events reported in this table are consistent with retirement being the most important reason for the separation. One fifth said their pension became available at the moment of retirement and also one fifth said there was an incentive for early retirement. The share of respondents who reported events that can be considered as an exogenous shock causing the separation is not large, though some respondents were encouraged departure by a supervisor or a coworker (6 percent), did not like to adjust to a new working environment (9 percent) or could have been laid off if had chosen to stay (4 percent).

Those who had a post-career bridge job are more likely to have experienced pressure to leave the career job. $12 \%$ report that they would have been laid off while $10 \%$ report that the supervisor encouraged departure. Many of them also experienced being eligible for pensions (15\%) and having incentives for early retirement $(15 \%)$ but less so compared to those who retired without having a bridge job.

To understand the importance of health and business conditions and having a part-time option in 
decisions on leaving the career job, the survey also asks the following counterfactual questions. For those respondents who report that their health was fair or poor, it asks how likely they would still have stopped working if their health had been better. For those who report that their health was either good, very good, or excellent, the question is asked with counterfactually worse health conditions. The survey also asks whether the business conditions was good or bad at the moment of leaving the career job and asks the same probability question with counterfactual business conditions. Lastly, the survey asks the probability question under a counterfactual option of working part-time.

Figure 2 demonstrates the role of health condition. There are not many respondents who report that they had either fair or poor health at the moment of retirement from the career job, but about $40 \%$ of them say there is no chance that they have stopped working if their health had been better. Less than $20 \%$ report that they would still have stopped working for sure regardless of their health conditions. The pattern is similar between those who did not have a bridge job and those who had one after the career job. On the other hand, a vast majority of those who report that their health was good or better say they would have stopped working for sure under a counterfactually worse health condition. In short, these responses reveal that for those who report that they had fair or poor health at the moment of retirement health was a major factor in their retirement decision making and a counterfactually better health condition could have changed their decision.

Figure 2: Probability of stop working under counterfactual health conditions

(a) Sample had no bridge job

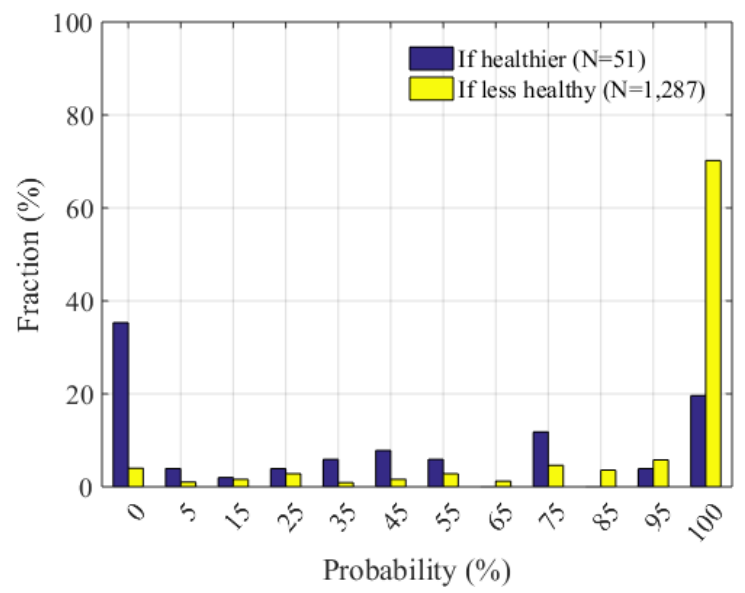

(b) Sample had a bridge job

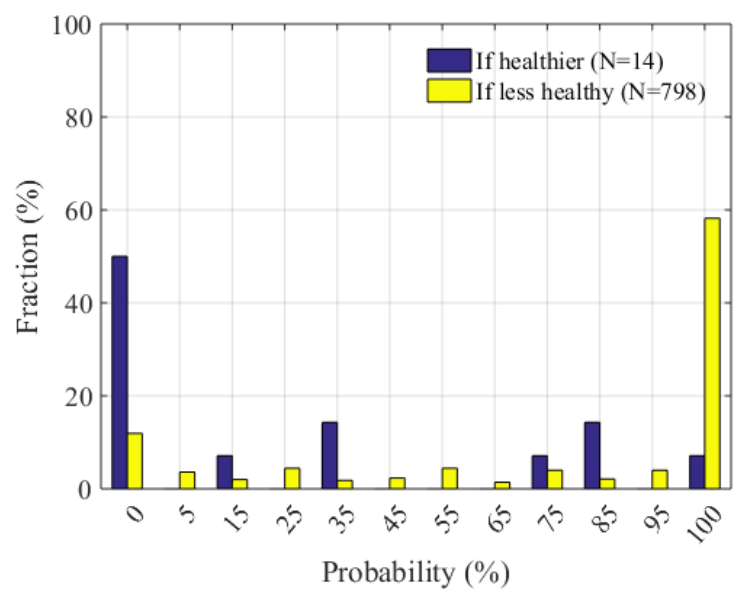

Figure 3 summarizes the effect of business conditions on retirement decisions. It shows a similar pattern to the effect of health, though the magnitude of the effects is slightly smaller. For those who experienced a bad business condition at the moment of separation, the business condition appears to 
be an important factor in their decision making. Among those who did no have a bridge job, $20 \%$ of those who left their career job when the business condition was bad report that there is no chance that they still have stopped working if the business condition was better. The number goes up to $40 \%$ when we look at those who had a post-career bridge job. Only about $30 \%$ of them would still have stopped working for sure even if the business condition had been better. On the other hand, the vast majority of who left their career job when the business condition was good would still have stopped working for sure under a counterfactually worse business condition.

Figure 3: Probability of stop working under counterfactual business conditions

(a) Sample had no bridge job

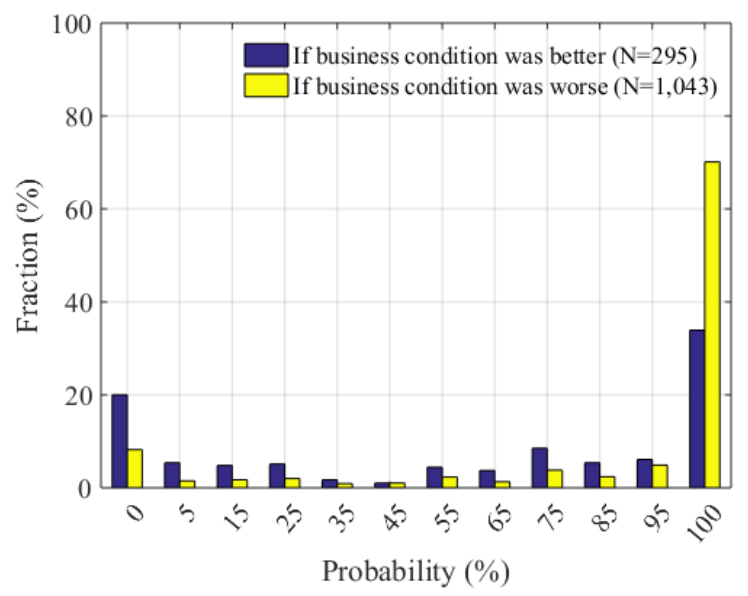

(b) Sample had a bridge job

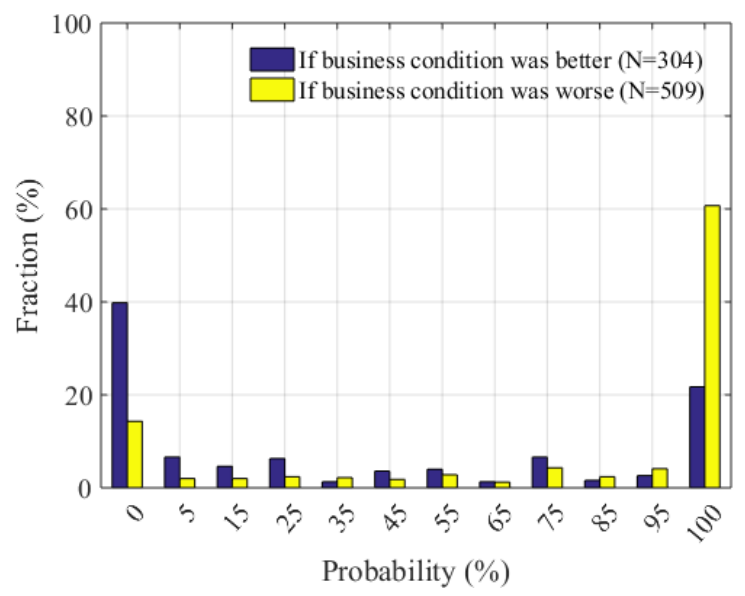

Lastly, Figure 4 demonstrates the effect of a part-time option. The effect of this option does not appear to be sizable. About half of the respondents would not have changed their decision even if this option had been offered. For between 10 and 20 percent of the sample, however, this option would have changed their decision to leave their career job for sure. A limited effect of the part time option might be due to the fact that the respondents expect other characteristics of the job may also change when they work part time. For example, they might expect to have a lower salary or faster pace of work if work part time. To identify the effect of reducing the work hours on labor supply, one needs to carefully control for other characteristics, which is the objective of the Strategic Survey Questions asked in the second part of Survey 4. See Ameriks, Briggs, Caplin, Lee, Shapiro and Tonetti (2017) for more details on the SSQs. 
Figure 4: Probability of stop working under part-time option

(a) Sample had no bridge job

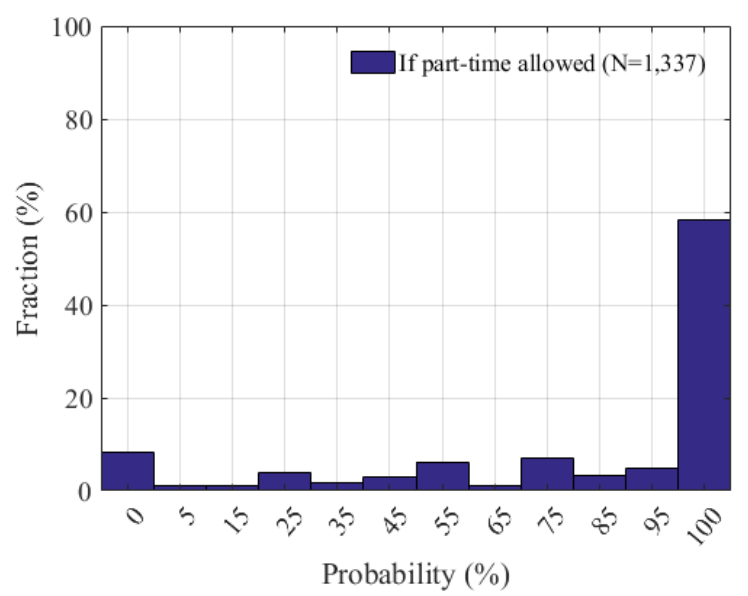

(b) Sample had a bridge job

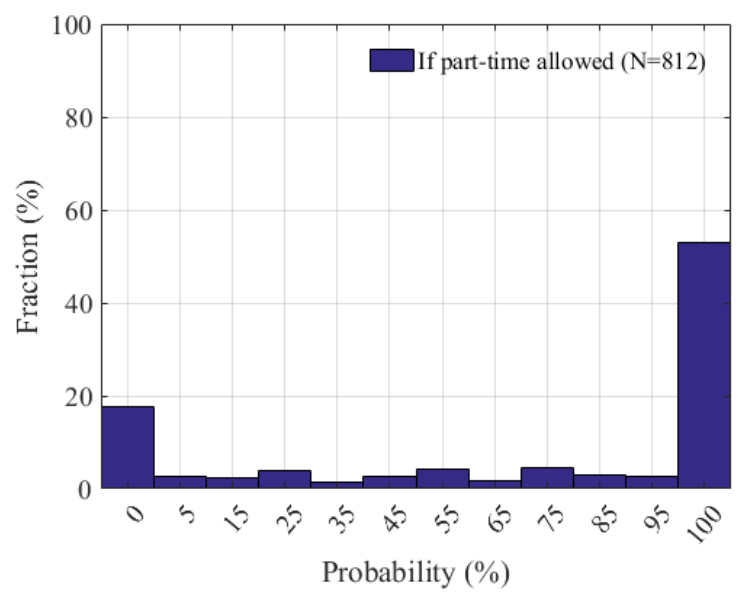

\section{Labor Market Activity after Career Job: Bridge Jobs}

Though a direct transition from a career job to full retirement is the most common pattern in the sample, a significant fraction of the sample still reveal their interest for working beyond a career job by either taking a bridge job or at least searching for such an opportunity. In this subsection we examine how the characteristics of bridge jobs are compared to those of career jobs and what characteristics respondents were looking for when they searched, to obtain another piece of evidence on what job characteristics are preferred in late life.

\subsection{Bridge Jobs}

Among 2,146 respondents who have already separated from their career jobs, 811 (38 percent) found a bridge job, instead of transitioning directly to no work. About half (378) of those who got a bridge job are still working in their bridge jobs. Given that those who directly transited to full retirement might come back to the labor market later, the share of sample who ever had a bridge job in the VRI (38 percent) is roughly comparable to that from Maestas (2007) (52 percent).

Panel A of Table 7 shows the length of search for the first post-career bridge job, the gap between the end of the career job and the first bridge job, and the gap between the end of the career job and the most recent bridge job. ${ }^{4}$ The length of search for the first bridge job is remarkably short. At median, it took only about a month to find the first post-career bridge job. More than three quarters

\footnotetext{
${ }^{4} 39 \%$ of those who had a bridge job had multiple bridge jobs. The most recent bridge job is the first one if they had only one bridge job.
} 
of sample spent less than one year in searching for the first bridge job. The actual gap between the end of the career job and the beginning of the first bridge job is shorter than the time spent on searching, reflecting that some workers start searching while they are still working on the career job. The median gap between the end of the career job and the beginning of the most recent bridge job is slightly longer than one year.

Table 7: Comparison: bridge jobs vs. career jobs

\section{A. Length of Search}

\begin{tabular}{lllllll}
\hline & $\underline{\mathbf{1 0 p}}$ & $\frac{\mathbf{2 5 p}}{0}$ & & $\frac{\mathbf{5 0 p}}{0.2}$ & $\frac{\mathbf{7 5 p}}{0.8}$ & $\frac{\mathbf{9 0 p}}{1.9}$ \\
How long searched for first bridge job (Yr) & 0 & 0 & 0.1 & 0.5 & 1.9 \\
Yr gap: b/w career and first bridge job & 0 & 0 & 0.1 & 1.3 & 5.2 & 10.4 \\
Yr gap: b/w career and most recent bridge job & 0 & 0.1
\end{tabular}

B. Hours and Earning

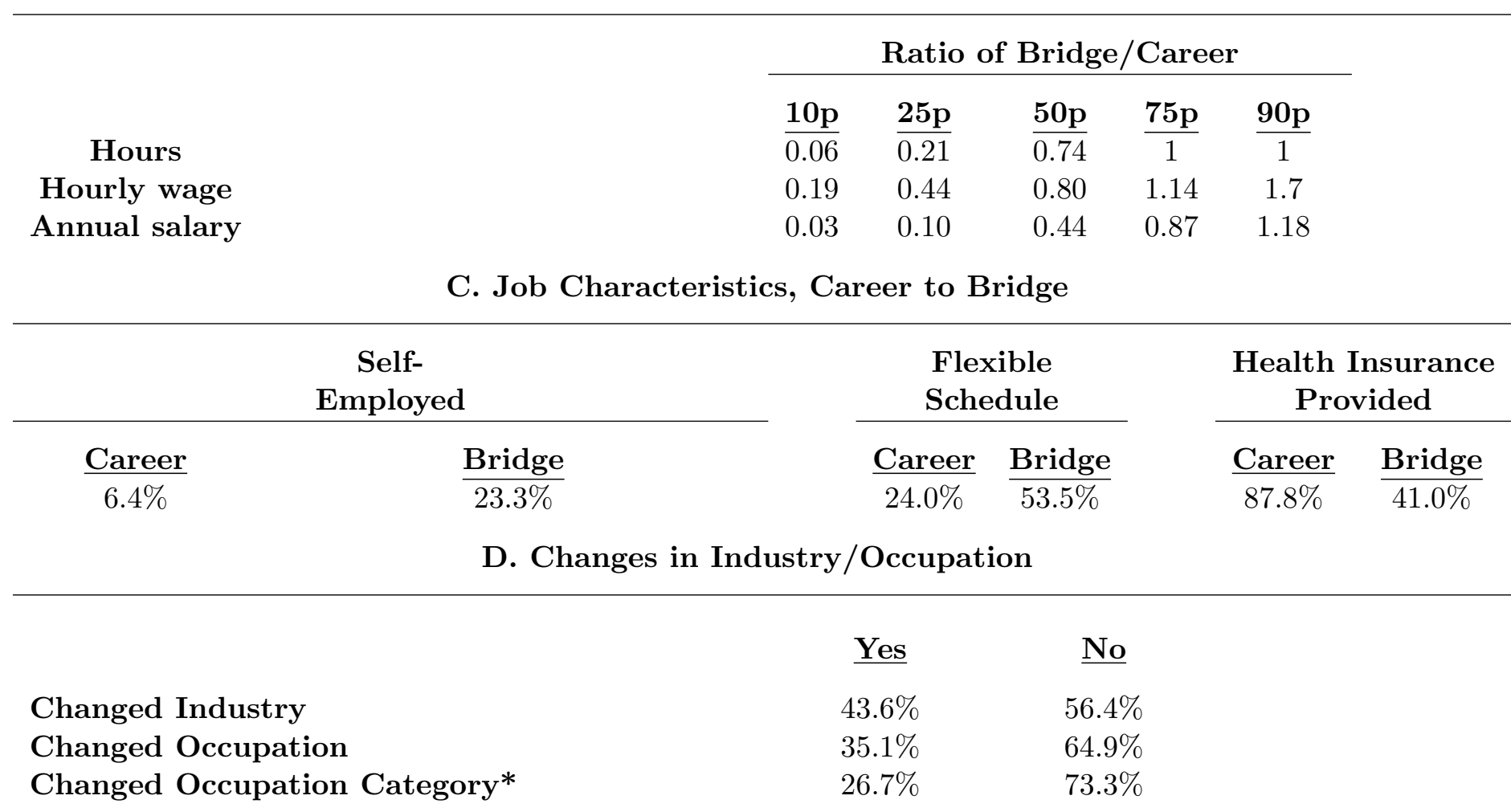

Notes: $\mathrm{N}=812$. Characteristics of career versus bridge jobs for respondents with bridge jobs.

*We define three broad occupation categories based on the type of abilities most required per occupation: human capital, social capital, and physical strength. The classification is based on a principal component analysis on the list of required abilities from ONET.

Figure 5 visualizes the transition patterns between the career and the post-career bridge jobs. 
Blue bars represent the tenure on the career jobs and the red bars represent that on the most recent bridge jobs. ${ }^{5}$ Several patterns deserve note. First, the gap between the blue and red bars are overall very short, confirming that the transition from the career to the post-career bridge jobs happen fairly quickly. Second, conditional on having a post-career bridge job, the separation from their career job happens mostly in their 50s. Third, there is a large variation in the length of the most recent bridge jobs.

The sample tend to work less number of hours for a lower hourly wage on a bridge job compared to their career job (Table 7, Panel B). At median, both the number of hours and hourly wage are reduced compared to career jobs (by $26 \%$ and $20 \%$, respectively). As a result of both reductions, annual salary from bridge jobs is at median about half of that from career jobs. This again hints that what is desired in late life is less burden of work rather than more pecuniary compensation. The comparisons at median, however, mask a rich pattern of changes in the number of hours and hourly wage. Figure 6 , the scatter plot of these two ratio variables, shows that distributions are all over the plane. The most common patterns are that both ratios are close to one (career-job-like bridge jobs) and both ratios are less than 0.5 (low-stress fun projects). Reducing number of hours a lot while maintaining relatively higher level of wage (part-time) and reducing hourly wage a lot while not changing the number of hours (volunteer work) are also not rare. Hence these result suggest not only the preference for less burden of work overall but also large heterogeneity in what older individuals want (and at the same time, in what they can find in the market).

Workers are more likely to have control over own work schedule on the bridge jobs (Table 7, Panel C). Bridge jobs are more likely to be self employed (23\%, compared to $6 \%$ in career jobs) and more likely to have an adjustable work schedule (54\%, compared to $24 \%$ in career jobs). With Medicare eligibility starting from age 65 , health insurance provision does not seem to be an important factor that older workers look for in bridge jobs. The share of bridge jobs with health insurance provision indeed drops at age 65 , from $54 \%$ to $35 \%$.

It is fairly common to change industry or occupation during the transitions from career to postcareer jobs. $44 \%$ of the sample changed industry while $35 \%$ changed occupation. When we classify occupations into three categories based on which one among human capital, social capital, and physical

\footnotetext{
${ }^{5}$ Respondents are sorted by their current age (black circle). An empty circle between the blue and red bars indicates that the respondents had another bridge job between the career and the most recent bridge jobs. Panel (a) is for those who are still working on their most recent bridge jobs while Panel (b) is for those who are not currently working.
} 
Figure 5: Transition patterns between career and bridge jobs

(a) Currently working

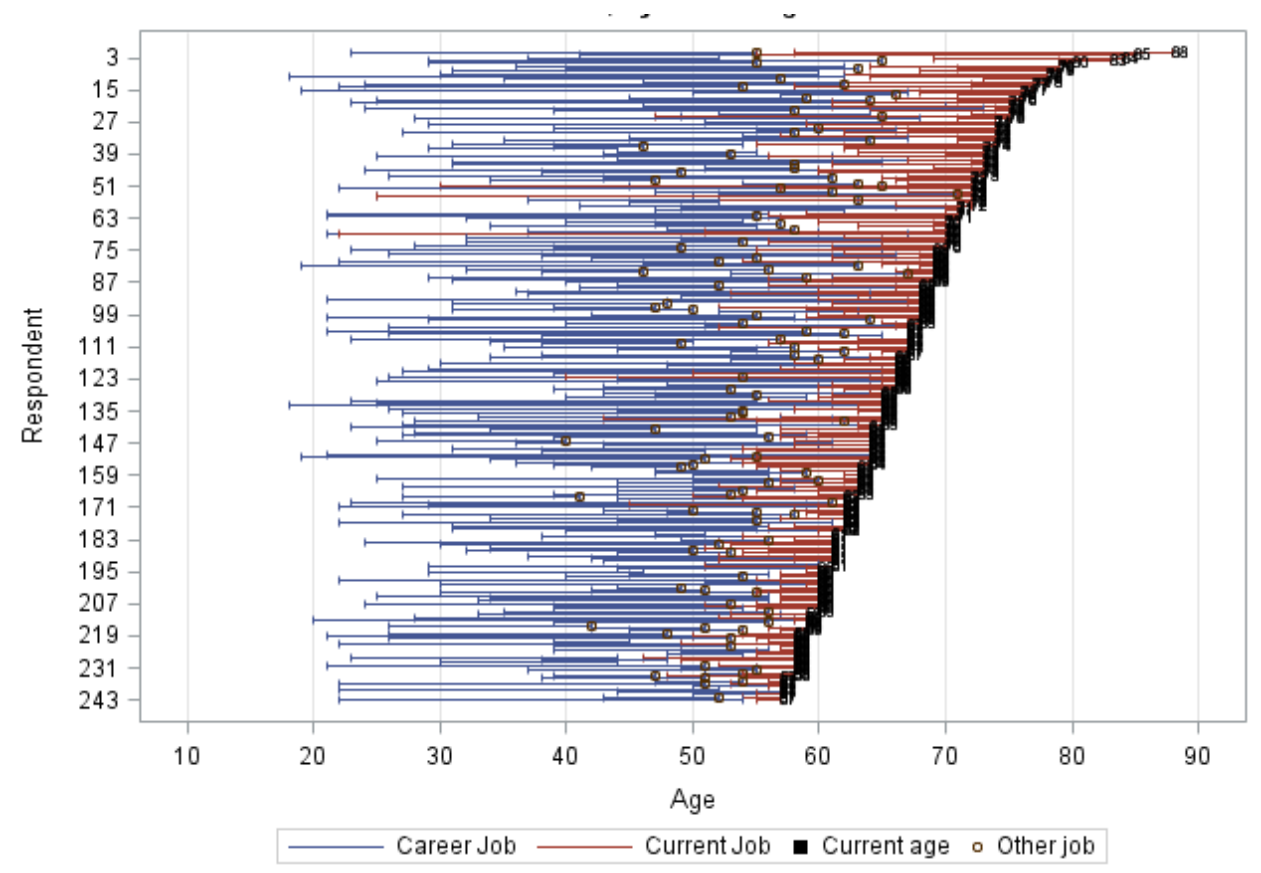

(b) Currently not working

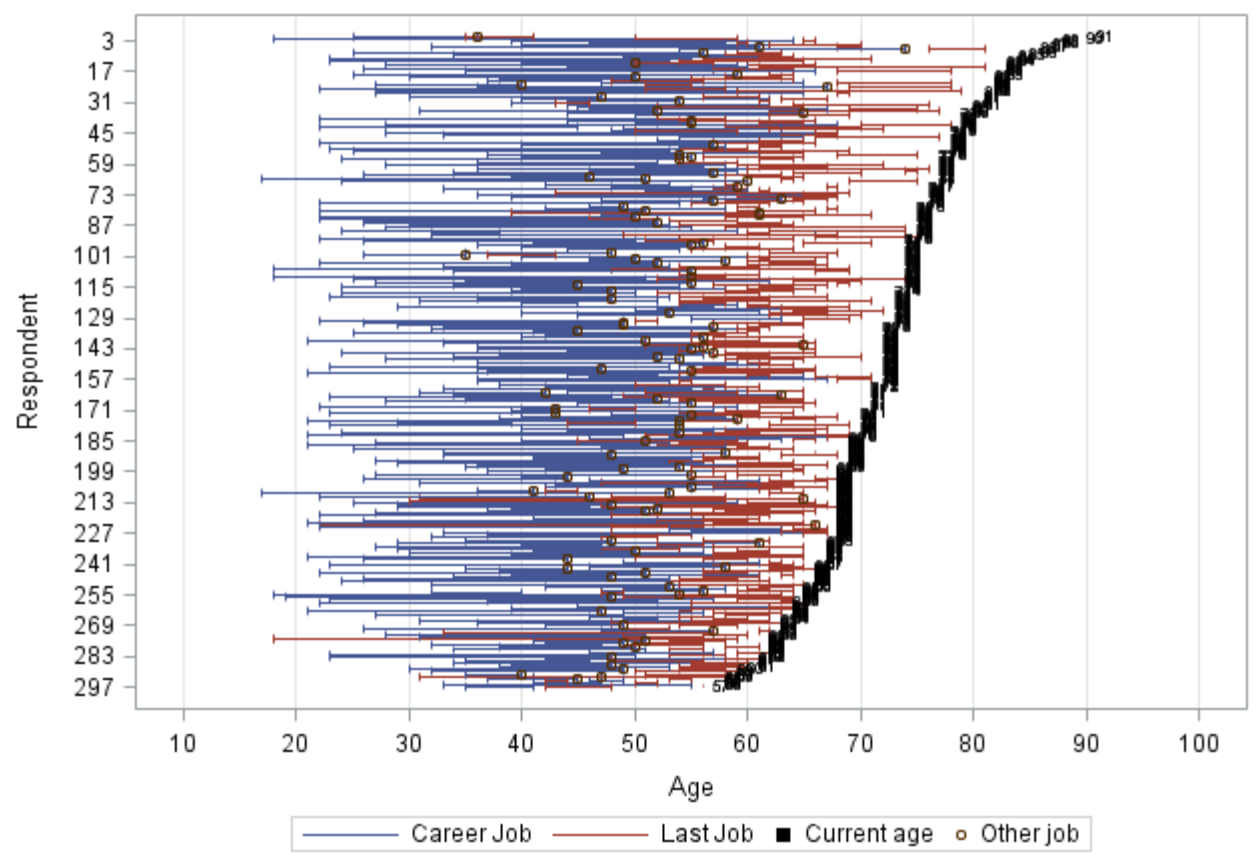

Note: Blue bars represent the career jobs and red bars represent the most recent bridge jobs. Black squares are the current ages and circles indicate that the respondents had another job between the career and the most recent bridge job. Respondents are sorted based on their current age. 
Figure 6: Hours reduction and hourly wage reduction

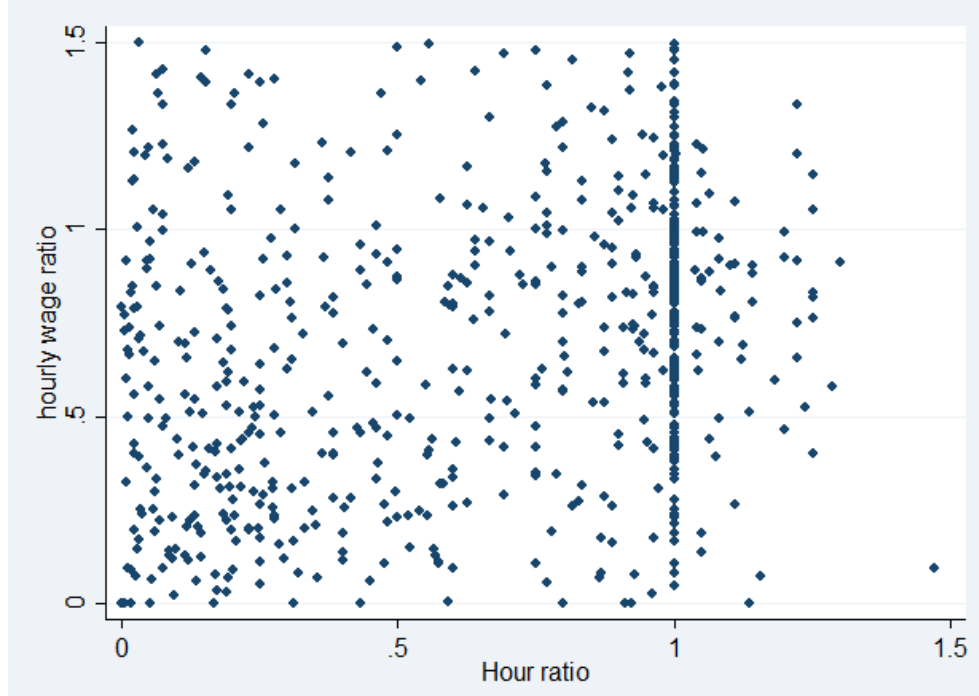

Note: Each ratio is calculated as the value from the bridge job divided by that from the career job. The figure exclude outliers with any ratio larger than 1.5.

strength is most required in each occupation ${ }^{6}$, about a quarter of the sample changed the occupation category, suggesting that a drastic change in the job characteristic is not rare.

\subsection{Empirical Analysis on Bridge-Career Wage Gaps}

The lower hourly wages for bridge jobs might reflect a penalty to working a reduced number or hours and/or a penalty to the lost human capital either due to changed occupation/industry or to the gap between the career and the bridge jobs. To disentangle the effects of these factors, we estimate the following regression:

$$
\begin{aligned}
\log \left(W_{b, i} / W_{c, i}\right)= & \beta_{0}+\operatorname{\alpha log}\left(H_{b, i} / H_{c, i}\right)+ \\
& \beta_{1} \operatorname{YearGap}_{i}+\beta_{2} \mathbb{1}_{C I, i}+\beta_{3} \mathbb{1}_{C O, i}+\beta_{4} \mathbb{1}_{G F, i}+\varepsilon_{i},
\end{aligned}
$$

where subscript $i$ stands for each respondent, $b$ for bridge jobs, and $c$ for career jobs. $W$ denotes for hourly wage, $H$ for the number of hours, YearGap for the number of years between the end of the career job and the start of the bridge job, $\mathbb{1}_{C I}$ is an indicator function for changing industry, $\mathbb{1}_{C O}$ is an indicator function for changing occupation, and $\mathbb{1}_{G F}$ is an indicator function for gaining flexibility in schedule. Note that the function used to capture the penalty to reduced number of hours is based

\footnotetext{
${ }^{6}$ The categorization is based on a principal component analysis on the list of required abilities from ONET.
} 
on French (2005) and French and Jones (2011). It means that when the number of hours is reduced by 1 percent, the hourly wage is reduced approximately by $\alpha$ percent. $^{7}$ We drop observations with whose $W_{b} / W_{c}$ or $H_{b} / H_{c}$ is greater than 95 percentile or smaller than 5 percentile.

Table 8 shows the regression results. $\alpha$, the penalty term for the part-time work, is estimated to be about 0.07, which is much smaller than 0.45 which is used in French (2005) and French and Jones (2011). Instead, we find that other factors that are often associated with transitions to bridge jobs involve significant penalties. Changing industry or occupation results in 18 and 27 percent reduction in hourly wage, respectively, reflecting potential loss in job-specific human capital. The length of gap between career and bridge jobs also reduces hourly wage. One year gap reduces hourly wage by 1.3 percent.

Table 8: Determinants of bridge-career wage gap

\begin{tabular}{lcc}
\hline Variable & Coeff. & Std. error \\
\hline $\log \left(H_{b} / H_{c}\right)$ & 0.072 & $(0.032)$ \\
YearGap & -0.013 & $(0.005)$ \\
Change in industry & -0.181 & $(0.062)$ \\
Change in occupation & -0.274 & $(0.066)$ \\
Gaining flexibility in schedule & -0.061 & $(0.054)$ \\
Constant & -0.100 & $(0.041)$ \\
\hline
\end{tabular}

Notes: $\mathrm{N}=646$. Dependent variable is the log of wage ratio between the bridge and the career jobs $\left(\log \left(W_{b} / W_{c}\right)\right)$. Dropped the observations whose $W_{b} / W_{c}$ or $H_{b} / H_{c}$ is greater than 95 percentile or smaller than 5 percentile.

Even though this is a reduced form regression that does not control for selection and is not meant to investigate causality, the results hint on what deter older Americans from having a post-career job. Changes in occupation and/or industry and a gap in career often occur during transitions into post-career employment and these are associated with a lower hourly wage. Reduction in the number of hours which seems to be preferred by older workers also result in a lower wage. All these factors may discourage older workers from having a post-career employment.

\footnotetext{
${ }^{7}$ We do not include the changes in the age as it is highly correlated with the years of gap. Including it only makes the coefficient on YearGap variable statistically insignificant, while not affecting the point estimate much. Also, to see whether they had another bridge job during the gap affects the estimation result, we tried including the interaction term between YearGap and the dummy variable of having a previous bridge job. Having a previous bridge job did not have any effect.
} 


\subsection{Job Search after Career Job}

Whether older Americans have a bridge job or not and what types of jobs they have depend not only on what they looked for but also on what were available in the market. In that sense, their search behavior - whether they ever looked for a job opportunity after the career job and, if they did, what types of jobs they were searching for - can be a better signal on older workers' preference.

Among those who directly transitioned into full retirement after career jobs, some, though not many, did look for a new job opportunity. $11 \%$ (147 out of 1,336) did so. One the other hand, the vast majority of those who had a bridge job, but not all of them, actively looked for such an opportunity. $80 \%$ (657 out of 812 ) actively searched for a bridge job while for the remaining $20 \%$ a bridge job opportunity was rather passively given to them.

Table 9 summarizes what job characteristics older workers looked for conditional on having searched. $40 \%$ wanted flexibility in deciding the number of hours, while $31 \%$ want to be flexible in deciding how to allocate these hours over days and weeks. $33 \%$ wanted less responsibility while $30 \%$ wanted to be more of own boss. We also find strong heterogeneity in what older workers look for. There is no single characteristic that gets votes from more than half of the sample. Except for a better health insurance, all characteristics are pursued by more than $10 \%$ of older workers.

The findings from analyzing search behavior echo those from other behavioral data. Though a significant fraction of older Americans reveal their interest for working after a career job, but still a majority of them transition into full retirement without actively searching for a post-career job opportunity. Based on what they looked for in their search, we find that flexibility in work schedule, having less burden, and being more of own boss are the most desired job characteristics at the end of working life.

\section{Discussion}

From Survey 4 of the VRI, we find older Americans' significant interest for working longer, expressed by working on career jobs even after being eligible for Social Security benefits and Medicare, having a bridge job after quitting career jobs, and searching for a post-career employment opportunity. In particular, about half of those who left their career jobs either had a bridge job (38 percent) or at least looked for such an opportunity even if they did not end up with having one $(62$ percent $\times 11$ percent $=7$ percent). 
Table 9: Search behavior: what workers were looking for

\begin{tabular}{lc}
\hline \hline & \\
Characteristic & \% looking for \\
\cline { 2 - 2 } Change life: & \\
\hline Different industry & 23.5 \\
Different occupation & 27.4 \\
Move to a better location & 20.8 \\
Flexibility: & \\
\hline More flexible hours & 39.9 \\
More flexible schedule & 31.0 \\
Autonomy: & \\
\hline Less responsibility & 32.5 \\
More of my own boss & 29.7 \\
Other job characteristics: & \\
\hline More pay & 19.9 \\
Less commuting time & 25.1 \\
More job security & 15.3 \\
Better health insurance & 7.8 \\
\hline \hline
\end{tabular}

Notes: $\mathrm{N}=804$. Respondents who searched after career job.

Still, the most common path of retirement is the direct transition from full time career job to full retirement. And the vast majority (89 percent) of those who did not have a bridge job even did not look for such an opportunity. By looking at this, one might jump into the conclusion that at least half of older Americans do not have any interest at all in working after leaving their career jobs. We have to stress, however, that all these behavioral data may underestimate their willingness to work longer. Not only the actual outcomes from the market but also respondents' search behavior reflect whether there are (and whether they expect to find) satisfactory job opportunities in the market.

From the behavioral data we also find hints on what job characteristics encourage workers to stay longer in the labor force. In particular, having more control over own work schedule, either by some flexibility in schedule being allowed by employers or by being self-employed, turn out to be the most desired features at the end of working life. But again, what job characteristics they find in bridge jobs and what they search for partially reflect what types of jobs are available (or expected to be available) in the market.

Transitions into post-career employments often involve changes in industry or occupation and gaps 
in career. All of these turn out to be associated with a wage reduction in bridge jobs compared to career jobs. This, in addition to the wage reduction associate with part-time working, may be an important factor that limits pose-career employments among older Americans.

\section{References}

[1] Ameriks, John, Joseph Briggs, Andrew Caplin, Minjoon Lee, Matthew D. Shapiro, and Christopher Tonetti (2017): “Older Americans Would Work Longer If Jobs were Flexible," NBER Working Paper, No. 24008.

[2] Ameriks, John, Andrew Caplin, Minjoon Lee, Matthew D. Shapiro, and Christopher Tonetti (2014): “The Wealth of Wealthholders," NBER Working Paper, No. 20972.

[3] Attanasio, Orazio, Sagiri Kitao, and Giovanni L. Violante (2007): “Global Demographic Trends and Social Security Reform," Journal of Monetary Economics, 54, 144-198.

[4] Blau, David M. and Tetyana Shvydko (2011): "Labor Market Rigidities and the Employment Behavior of Older Workers," Industrial and Labor Relations Review, 64, 464-484.

[5] Bronshtein, Gila, Jason Scott, John B. Shoven, and Sita N. Slavov (2018): "The Power of Working Longer," NBER Working Paper, No. 24226.

[6] French, Eric (2005): "The Effects of Health, Wealth, and Wages on Labour Supply and Retirement Behavior," Review of Economic Studies, 72, 395-427.

[7] French, Eric and John Bailey Jones (2011): "The Effects of Health Insurance and Self-Insurance on Retirement Behavior," Econometrica, 79, 693-732.

[8] Gobeski, Kirsten T. and Terry A. Beehr (2009): "How Retirees Work: Predictors of Different Types of Bridge Employment," Journal of Organizational Behavior, 30, 401-425.

[9] Kantarci, Tunga and Arthur van Soest (2015): "Full or Partial Retirement? Effects of the Pension Incentives and Increasing Retirement Age in the Netherlands and the United States," Netspar Discussion Paper No. 2013-038.

[10] Kapteyn, Arie, James P. Smith and Arthur van Soest (2008): "Dynamics of Work Disability and Pain," Journal of Health Economics, 27, 496-509. 
[11] Maestas, Nicole (2010): "Back to Work: Expectations and Realizations of Work after Retirement," Journal of Human Resources, 45, 718-748.

[12] Ramnath, Shanthi, John B. Shoven, and Sita Nataraj Slavov (2017): "Pathways to Retirement through Self-Employment," NBER Working Paper No. 23551.

[13] Ruhm, Christopher J. (1990): "Bridge Jobs and Partial Retirement," Journal of Labor Economics, $8,482-501$.

[14] Rupert, Peter and Giulio Zanella (2015): "Revisiting Wage, Earnings, and Hours Profiles," Journal of Monetary Economics, 72, 114-130.

[15] van Soest, Authur, Arie Kapteyn and Julie M. Zissimopoulos (2007): "Using Stated Preferences Data to Analyze Preference for Full and Partial Retirement," RAND Working Paper Series No. WR-345.

[16] van Soest, Authur and Hana Vonkova (2014): "How Sensitive are Retirement Decisions to Financial Incentives? A Stated Preference Analysis," Journal of Applied Econometrics, 29, 246-264. 


\section{A Appendix: Comparison with HRS Sample}

Table A1: The HRS sample characteristics

A. Age eligible

Age:

Financial wealth:
Age and Wealth

\begin{tabular}{cccccc}
\hline $\mathbf{1 0 p}$ & $\frac{\mathbf{2 5 p}}{60}$ & $\frac{\mathbf{5 0 p}}{66}$ & $\frac{\mathbf{7 5 p}}{75}$ & $\frac{\mathbf{9 0 p}}{82}$ & $\frac{\text { Mean }}{68}$ \\
-935 & 520 & 62,358 & 311,790 & 774,279 & 305,135
\end{tabular}

Married

\begin{tabular}{ll}
$\frac{\text { Yes }}{51 \%}$ & $\frac{\text { No }}{49 \%}$ \\
Sex & \\
\hline
\end{tabular}

Female Male

$52 \% \quad 48 \%$

Education

\begin{tabular}{ccc}
\hline$\frac{2}{71 \%}$ & $\frac{\text { College }}{17 \%}$ & $\frac{>}{12 \%}$ College \\
& Health \\
\hline
\end{tabular}

\begin{tabular}{|c|c|}
\hline $\begin{array}{l}\text { Excellent/ } \\
\text { Very Good }\end{array}$ & Good \\
\hline $42 \%$ & $32 \%$ \\
\hline
\end{tabular}

B. VRI eligible

Age:

Financial wealth:

\section{$\frac{10 p}{56}$}

Age and Wealth

$\begin{array}{cccccc}\frac{\mathbf{1 0 p}}{56} & \frac{\mathbf{2 5 p}}{59} & \frac{\mathbf{5 0 p}}{64} & \frac{\mathbf{7 5 p}}{70} & \frac{\mathbf{9 0 p}}{77} & \frac{\text { Mean }}{65} \\ 5,336 & 101,889 & 283,690 & 685,939 & 1,296,840 & 600,788\end{array}$

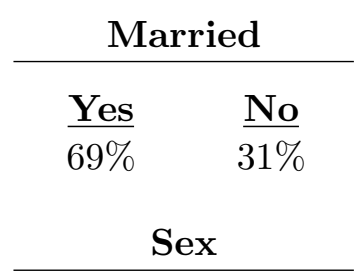

\begin{tabular}{|c|c|c|}
\hline \multicolumn{3}{|c|}{ Education } \\
\hline$<$ College & College & $>$ College \\
\hline $29 \%$ & $41 \%$ & $22 \%$ \\
\hline & Health & \\
\hline
\end{tabular}

$\frac{\text { Female }}{44 \%} \quad \frac{\text { Male }}{56 \%}$

\footnotetext{
Notes: The first panel uses all the financial respondents (the respondents who answered questions regarding household finance in case there are multiple respondents in one household) who are age 55 or above $(\mathrm{N}=12,492)$. For the second panel we impose additional criteria that they are internet eligible and have at least $\$ 10,000$ in non-transactional accounts $(\mathrm{N}=3,478)$. All the tabulations are weighted using the HRS sampling weights.
} 
Table A2: Labor force participation status

\begin{tabular}{lccccccc}
\hline \hline & \multicolumn{5}{c}{ By Age } & & Total \\
\cline { 2 - 6 } \cline { 5 - 6 } & $\underline{\mathbf{5 5 - 5 9}}$ & $\underline{\mathbf{6 0 - 6 4}}$ & $\underline{\mathbf{6 5 - 6 9}}$ & $\underline{\mathbf{7 0 - 7 4}}$ & $\underline{\mathbf{7 5 -}}$ & \\
A. Age eligible & & & & & & \\
Retired, completely (\%) & 16.9 & 36.7 & 57.2 & 70.6 & 86.1 & 52.3 \\
Retired, not completely (\%) & 4.9 & 9.0 & 15.2 & 13.9 & 5.9 & 8.9 \\
Not retired (\%) & 78.2 & 54.3 & 27.6 & 15.5 & 8.0 & 38.8 \\
N & 2,502 & 2,144 & 1,378 & 2,076 & 4,392 & 12,492 \\
& & & & & & \\
B. VRI eligible & & & & & & \\
Retired, completely (\%) & 10.3 & 26.6 & 47.8 & 63.0 & 81.7 & 38.2 \\
Retired, not completely (\%) & 6.2 & 10.9 & 20.5 & 19.2 & 10.8 & \\
Not retired (\%) & 83.5 & 62.5 & 31.7 & 17.8 & 7.5 & 49.3 \\
N & 852 & 687 & 517 & 635 & 787 & 3,487 \\
& & & & & & \\
\hline \hline
\end{tabular}

Notes: See the notes for Table A1. 
Table A3: Career Job Characteristics: Age-Eligible HRS

\begin{tabular}{|c|c|c|c|c|c|c|}
\hline \multirow[t]{2}{*}{ A. Retired from career job } & \multicolumn{6}{|c|}{ Years worked } \\
\hline & 10p & $25 p$ & $50 p$ & $75 p$ & $90 p$ & Mean \\
\hline Years worked: & 5 & 10 & 18 & 27 & 35 & 19 \\
\hline \multirow[t]{3}{*}{ Most common industries: } & \multicolumn{5}{|c|}{ Manufacturing } & $15.3 \%$ \\
\hline & \multicolumn{5}{|c|}{ Health care and social assist } & $14.8 \%$ \\
\hline & \multicolumn{5}{|c|}{ Retail trade } & $8.9 \%$ \\
\hline \multirow[t]{3}{*}{ Most common occupations: } & \multirow{3}{*}{\multicolumn{5}{|c|}{$\begin{array}{l}\text { Office and admin support } \\
\text { Production } \\
\text { Sales and related }\end{array}$}} & $13.5 \%$ \\
\hline & & & & & & $9.8 \%$ \\
\hline & & & & & & $9.2 \%$ \\
\hline \multirow[t]{2}{*}{ B. Working on career job } & \multicolumn{6}{|c|}{ Years worked, salary, hours worked } \\
\hline & $10 p$ & $25 p$ & $50 p$ & $75 p$ & $90 p$ & $\underline{\text { Mean }}$ \\
\hline Years worked: & 5 & 11 & 20 & 30 & 37 & 21 \\
\hline Salary (in 2015\$): & 10,947 & 21,874 & 40,523 & 69,360 & 102,050 & 51,108 \\
\hline Hours worked (per year): & 900 & 1,664 & 2,080 & 2,236 & 2,600 & 1,953 \\
\hline \multirow[t]{2}{*}{ Self-employed: } & \multicolumn{5}{|l|}{ Yes } & $22.0 \%$ \\
\hline & \multicolumn{5}{|l|}{ No } & $78.0 \%$ \\
\hline \multirow[t]{3}{*}{ Most common industries: } & \multicolumn{5}{|c|}{ Manufacturing } & $17.4 \%$ \\
\hline & \multicolumn{5}{|c|}{ Health care and social assist } & $11.6 \%$ \\
\hline & \multicolumn{5}{|c|}{ Retail trade } & $7.4 \%$ \\
\hline \multirow[t]{3}{*}{ Most common occupations: } & \multicolumn{5}{|c|}{ Office and admin support } & $11.9 \%$ \\
\hline & \multicolumn{5}{|c|}{ Management } & $11.1 \%$ \\
\hline & \multicolumn{5}{|c|}{ Sales and related } & $9.6 \%$ \\
\hline
\end{tabular}

Notes: Career job is defined as the job with the longest tenure. This table uses all the financial respondents who are age 55 or above and reported the tenure on their longest job $(\mathrm{N}=8,831$ for Panel $\mathrm{A}$ and $\mathrm{N}=1,844$ for Panel B). 
Table A4: Career Job Characteristics: VRI-Eligible HRS

\begin{tabular}{|c|c|c|c|c|c|c|}
\hline \multirow[t]{2}{*}{ A. Retired from career job } & \multicolumn{6}{|c|}{ Years worked } \\
\hline & $10 p$ & $25 \mathrm{p}$ & $50 p$ & $75 \mathrm{p}$ & $90 p$ & Mean \\
\hline Years worked: & 8 & $\overline{13}$ & $\overline{20}$ & $\overline{29}$ & $\overline{35}$ & 21 \\
\hline \multirow[t]{3}{*}{ Most common industries: } & \multicolumn{5}{|c|}{ Manufacturing } & $17.6 \%$ \\
\hline & & $11.5 \%$ \\
\hline & & & & \multicolumn{2}{|c|}{ Educational services } & $9.0 \%$ \\
\hline \multirow[t]{3}{*}{ Most common occupations: } & \multicolumn{5}{|c|}{ Management } & $19.3 \%$ \\
\hline & \multicolumn{5}{|c|}{ Office and admin support } & $14.2 \%$ \\
\hline & \multicolumn{5}{|c|}{ Sales and related } & $10.6 \%$ \\
\hline \multirow[t]{2}{*}{ B. Working on career job } & \multicolumn{6}{|c|}{ Years worked, salary, hours worked } \\
\hline & 10p & $25 p$ & $50 p$ & $75 \mathrm{p}$ & $90 p$ & Mean \\
\hline Years worked: & 10 & 15 & $\overline{23}$ & $\overline{32}$ & 37 & 23 \\
\hline Salary (in 2015\$): & 19,992 & 37,572 & 61,200 & 92,820 & 134,640 & 81,777 \\
\hline Hours worked (per year): & 1,040 & 1,820 & 2,080 & 2,392 & 2,750 & 2,033 \\
\hline \multirow[t]{2}{*}{ Self-employed: } & \multicolumn{5}{|l|}{ Yes } & $24.1 \%$ \\
\hline & \multicolumn{5}{|l|}{ No } & $75.9 \%$ \\
\hline \multirow[t]{3}{*}{ Most common industries: } & \multirow{3}{*}{\multicolumn{5}{|c|}{$\begin{array}{l}\text { Health care and social assist } \\
\text { Professional, scientific, tech. services } \\
\text { Manufacturing }\end{array}$}} & $15.3 \%$ \\
\hline & & & & & & $13.6 \%$ \\
\hline & & & & & & $13.0 \%$ \\
\hline \multirow[t]{3}{*}{ Most common occupations: } & \multicolumn{5}{|c|}{ Management } & $17.4 \%$ \\
\hline & \multicolumn{5}{|c|}{ Office and admin support } & $11.9 \%$ \\
\hline & \multicolumn{5}{|c|}{ Business and financial operation } & $9.5 \%$ \\
\hline
\end{tabular}

Notes: Career job is defined as the job with the longest tenure. This table uses all the financial respondents who are VRI-eligible and reported the tenure on their longest job ( $\mathrm{N}=2,693$ for Panel $\mathrm{A}$ and $\mathrm{N}=930$ for Panel B). 